\title{
Index nominum ad Vol. 164
}

Barrat, J., 200 (B) Baumann, U., 221 Berger, J., 135 (B) Boden, W., 65, 147 Cardis, R., 321

Czeizel, E., 89 Dässler, C.-G., 175 Dokumov, S. I., 83 Elek, E., 89 Essbach, H., 200 (B) FavreGilly, J., 1 Friedberg, V., 329 Gaál, M., 307 Gamp, R., 156

Georgakopoulos, P. A., 297 Gerteis, W., 64 (B) Giarola, A., 96 Gömöri, Z., 231 Götz, F., 71

Grétillat, P. A., 265 Gros, C, 384 (B) Gschwendtner, R., 200 (B) Haeusler, H., 179 Hammacher, K., 64 Hauser, G. A., 191 Herrmann, W. L., 55 Keys, R. F., 43 Hodel, C, 114

388

Index nominum ad Vol. 164

Hofmann, D., 24, 316 Hollander, H. J., 24 Hüter, K. A., 199 (B) Jakubowski, A., 336 Janata, J., 195 Kabátová, A., 336 Kafarsoussi, A., 1 Kohler, H. G., 43 Kratochwil, A., 37 Krauer, F., 343 Kfecek, M., 195 Kubicki, S., 179 Ledermair, 0., 109 Lee, T. Y., 55 Levy, J., 200 (B) Loskant, G., 249 Lukas, K. H., 384 (B) Madej, J., 283 Mærtens, K., 71 Magnin, P., 64 (B) Martius, G., 201 Martius, H., 200 (B) Mathesius, V. J., 274 Maudin, E. P., 64 (B) Melchior, J., 200 (B)

Merger, R., 200 (B) Mladenovsky, V. D., 83 More, J. R. S., 240 Motocu, V., 287 Muller, P., 367 Muralt, G. de, 199 (B) Mure§an, S., 287

Murray, C. P., 43

N. Neri, A., 377 Nicolae, A., 287 Obolensky, W., 260, 279 Pigeaud, H., 1 Piguet, J. M., 265 Pospisil, L, 336 Ratanasopa, V., 55 Riotton, G., 265 Rippmann, E. T., 215 Rose, I., 200 (B) Rohde, U., 175 Rossi, E., 199 (B) Saling, E., 179 Schindler, A. E., 55 Schmid, J., 221 Schneider, D., 179 Schubiger, V., 191 Sorrentino, M., 199 (B) Spasov, S. A., 83 Stamm, H., 137 Stárka, L., 195 Turunen, A., 13 Vennebusch, 1·L, 179 Vinazzer, H., 109 Viscolo, H. C, 265 Waroński, W., 355 Weiser, P., 24 Zakrys, F., 355 Zehan, M., 287 Zeman, V., 336 